
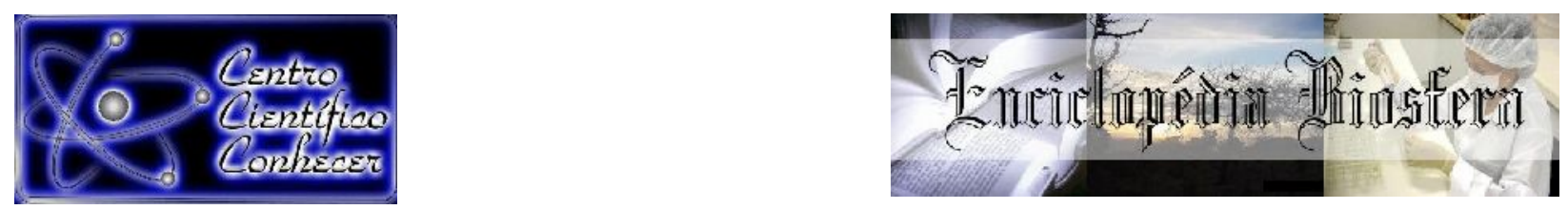

\title{
APRENDIZAGEM SIGNIFICATIVA E NEUROCIÊNCIA: UMA PROPOSTA PEDAGÓGICA PARA O ENSINO DE FÍSICA
}

\author{
Cristiana Maria dos Santos Silva ${ }^{1}$, Mairton Cavalcante Romeu ${ }^{2}$, Maria Cleide da \\ Silva Barroso ${ }^{3}$ \\ ${ }^{1}$ Mestranda do Programa de Pós-Graduação em Ensino de Ciências e \\ Matemática - PGECM /Instituto Federal de Educação, Ciência e \\ Tecnologia do Ceará - IFCE Campus/Fortaleza-Ce, Brasil. \\ 2,3 Doutores/Docentes do Programa de Pós-Graduação em Ensino de Ciências e \\ Matemática - PGECM /Instituto Federal de Educação, Ciência e \\ Tecnologia do Ceará - IFCE Campus/Fortaleza-Ce, Brasil. \\ Email: cristianaprof123@gmail.com
}

Recebido em: 15/08/2021 - Aprovado em: 15/09/2021 - Publicado em: 30/09/2021 DOI: 10.18677/EnciBio_2021C5

trabalho licenciado sob licença Creative Commons Attribution-NonCommercial-NoDerivatives 4.0 International License.

\begin{abstract}
RESUMO
O artigo trata-se de um estudo baseado e fundamentado em uma revisão bibliográfica com enfoque qualitativo e tem por objetivo relacionar os conhecimentos da Neurociência com a Teoria da Aprendizagem Significativa como proposta teórica para facilitar o processo de aprendizagem significativa de Física. Este trabalho tomou por base os resultados de pesquisas anteriores descritos em artigos científicos, livros, e sites na internet, através de consultas a plataformas digitais. Entender como a neurociência pode contribuir para a aprendizagem significativa no âmbito pedagógico é uma grande preocupação, pois constantemente o docente se depara com as questões de dificuldades de aprendizagem do aluno. Diversos fatores podem estar envolvidos por trás desta problemática, por isso, o estudo mostra a importância da relação entre a neurociência e a aprendizagem significativa, como mola propulsora do ensino no processo de aprendizagem. Espera-se com esta pesquisa que as percepções entre Aprendizagem Significativa e a Neurociência no ensino de Física possibilitem reflexões aos professores, buscando alternativas para melhorar a qualidade e potencializar a aplicabilidade de tais teorias em sala de aula.

PALAVRAS-CHAVE: Aprendizagem significativa. Ensino de Física. Neurociência.
\end{abstract}

\section{SIGNIFICANT LEARNING AND NEUROSCIENCE: A PEDAGOGICAL PROPOSAL FOR PHYSICS TEACHING}

\begin{abstract}
The article is a study based on and based on a literature review with a qualitative focus and aims to relate the knowledge of Neuroscience with the Theory of Meaningful Learning as a theoretical proposal to facilitate the process of meaningful learning in Physics. This work was based on the results of previous research described in scientific articles, books, and internet sites, through consultations on digital platforms. Understanding how neuroscience can contribute to meaningful learning in the pedagogical scope is a major concern, as the teacher is constantly faced with the issues of student learning difficulties. Several factors may be involved
\end{abstract}


behind this problem, therefore, the study shows the importance of the relationship between neuroscience and meaningful learning, as the driving force behind teaching in the learning process. With this research, it is hoped that the perceptions between Meaningful Learning and Neuroscience in the teaching of Physics will enable teachers to reflect on, seeking alternatives to improve the quality and enhance the applicability of such theories in the classroom.

KEYWORDS: Meaningful learning. Neuroscience. Teaching Physics.

\title{
INTRODUÇÃO
}

O presente trabalho aborda a relação entre a Neurociência e a Aprendizagem Significativa, como proposta para facilitar o processo de ensino e aprendizagem do estudo da Física. Compreender como a neurociência pode contribuir para a aprendizagem no ambiente escolar é de suma importância, pois frequentemente o professor se depara com as questões de dificuldades da aprendizagem do aluno, e não sabe de fato, quais fatores podem estar envolvidos em determinadas problemáticas.

Pesquisar novos conhecimentos sobre neurociência pode dar base para constituir estratégias que visem à aprendizagem significativa. Conforme Moreira (2012.):

\begin{abstract}
Aprendizagem significativa é aquela em que ideias expressas simbolicamente interagem de maneira substantiva e não-arbitrária com aquilo que o aprendiz já sabe. Substantiva quer dizer não-literal, não ao pé-da-letra, e não-arbitrária significa que a interação não é com qualquer ideia prévia, mas sim com algum conhecimento especificamente relevante já existente na estrutura cognitiva do sujeito que aprende (MOREIRA, 2012, p .2).
\end{abstract}

Sendo assim, segundo o autor a aprendizagem significativa se designa pela interação entre conhecimentos prévios e conhecimentos novos, e que essa relação é não-literal e não-arbitrária. Portanto, esse estudo pode contribuir com o trabalho dos docentes, a fim de oportunizar melhor qualidade no processo de ensino aprendizagem.

O ensino de Física tem ocasionado uma politização do problema. As dificuldades de um ensino uniformizado, a agregação ou desagregação teoria e laboratório e o desconhecimento dos estudantes na Matemática, tem gerado dificuldades e preocupações no aprendizado da Física. Sendo assim, a perspectiva é de dar mais atenção a este ensino (MOREIRA, 2018).

Para o estudo, foi realizada uma análise em artigos científicos, livros, e sites na internet por meio de consultas e plataformas digitais, que buscam relacionar os conhecimentos da Neurociência com a Teoria da Aprendizagem Significativa como proposta teórica para facilitar o processo de aprendizagem significativa da Física, visando dar ao leitor subsídios para a compreensão e entendimento do assunto explorado.

Ademais, foi feita uma pesquisa em diferentes bases de dados utilizando-se palavras-chave como "Aprendizagem significativa de Ausubel", "Neurociência e ensino", "Ensino de Física", "Neurociência e aprendizagem significativa" e "Neurociência e o ensino de Física". O desenvolvimento metodológico seguiu os 
pressupostos da abordagem qualitativa mediante levantamento bibliográfico. Os dados foram discutidos a partir dos pressupostos da análise dos temas.

Para Silva e Menezes (2001, p. 20):

A pesquisa qualitativa considera que há uma relação dinâmica entre o mundo real e o sujeito, isto é, um vínculo indissociável entre o mundo objetivo e a subjetividade do sujeito que não pode ser traduzido em números.

A compreensão dos fenômenos e a responsabilidade de significados são essenciais no processo qualitativo. Diversas descobertas estão sendo realizadas nos últimos anos, transformando antigas concepções no que se refere à de vários processos cognitivos diretamente envolvidos na construção do pensamento físico. Ainda assim, estes resultados são na prática desconhecidos na área de Ensino de Física (BROCKINGTON, 2021).

Neurociência e Educação (por conseguinte, a área de ensino 46 da CAPES ${ }^{1}$ ), enquanto área de pesquisa, é um empreendimento contemporâneo e em rápido desenvolvimento. Enquanto área, o campo de interação entre esses conhecimentos recebe nomes como "neurociência educacional" ou "neuroeducação" (COSENZA; GUERRA, 2011).

Para Brockington (2021), a expectativa é que incluindo as descobertas recentes provenientes dos estudos do funcionamento do cérebro com as teorias psicológicas e educacionais possa se obter um cenário, sobre como ocorre 0 processo de aprendizagem, seja de conteúdos abstratos até o controle motor, passando por aritmética e alfabetização.

Diante dessa perspectiva foram utilizadas fontes bibliográficas que mostram a importância da relação entre a neurociência e a aprendizagem significativa, apontando aspectos importantes relacionados a neurociência e educação, além de caracterizar alguns processos de aprendizagem, destacando a importância da aprendizagem significativa para o ensino de Física (BROCKINGTON, 2021).

\section{O ENSINO DE FÍSICA E AS DIFICULDADES NA APRENDIZAGEM}

As dificuldades que impactam o ensino de Física não são atuais e têm sido detectadas já faz algum tempo, levando diferentes estudiosos e pesquisadores a refletirem sobre as causas e efeitos no processo de ensino e aprendizagem (MOREIRA, 2018). Segundo este mesmo autor, os conteúdos curriculares não vão além da Física Clássica e são apresentados da maneira ainda tradicional, centralizada no professor, resultado é que os estudantes, em vez de alargar o conhecimento para aprender Física, como seria previsto para uma aprendizagem

\footnotetext{
1 "A área de Ensino é, por definição, interdisciplinar. Nas propostas interdisciplinares trabalha-se com concepção de integração de saberes, fortalecendo a interdependência entre as disciplinas, sua interação, comunicação de modo a buscar a articulação do conhecimento e investigar na interface dos campos envolvidos" (BRASIL, 2019, p.8). Nesse sentindo, recordando: os construtos teóricos de neurociência estão discriminados e relacionados à educação. No entanto, é necessário fazer essa ponderação, o bojo da discussão posta neste artigo trata da área de ensino de Física, embora existam correlações entre ensino e educação, utilizados para fazer a construção do referencial teórico e bibliográfico.
} 
significativa, [...] geram uma indisposição tão forte que chegam a dizer, metaforicamente, que "odeiam" a Física (MOREIRA, 2018, p.73).

Paradoxalmente, no entanto, esse ensino está em crise. A carga horária semanal que chegou a 6 horas-aula por semana, hoje é de 2 ou menos. Aulas de laboratório praticamente não existem. Faltam professores de Física nas escolas e os que existem são obrigados a treinar os alunos para as provas, para as respostas corretas, ao invés de ensinar física. A interdisciplinaridade e a transdisciplinaridade são confundidas com não disciplinaridade e tiram a identidade da Física (MOREIRA, 2018, p.73).

É notório que o ensino de Física ainda se mantém no tradicional, centrado no professor, na memorização de fórmulas a serem aplicadas e na resolução de problemas conhecidos. Os alunos, continuam utilizando a forma mecânica baseada em "regras" pré-definidas para solucionar os exercícios, com o intuito de somente atingir a aprovação. O impacto no processo de aprendizagem no ensino de Física na sala de aula ainda é muito pequeno (ROCHA et al., 2017).

A Física no ensino médio deve assegurar que a competência investigativa resgate o espírito questionador, o desejo de conhecer o mundo onde se habita, logo é uma ciência que permite investigar os mistérios do mundo, compreender a natureza da matéria macroscópica e atômica (ROCHA et al., 2017, p.51).

As investigações veiculadas pelos meios de comunicação ainda continuam sendo superficiais. Sendo assim, as informações recebidas podem levar a uma compreensão tendenciosa da realidade e do papel do conhecimento físico no mundo contemporâneo. No contexto atual, as Tecnologias de Informação e Comunicação (TIC) devem interpor-se ao ensino de Física (ROCHA et al., 2017).

Como já foi apontada, a área da Física continua com aulas expositivas e listas de exercícios, lousa, slides em PowerPoint, livro didático ou apostila, aprendizagem mecânica de fórmulas com respostas certas. Destarte, considera que a compreensão dos pressupostos do estudo da Física, a partir de atividades experimentais, associadas às tecnologias, estabelece uma proposta de ensino metodologicamente significativa, pois reivindica mudanças de atitude tanto do aluno quanto do docente, visto que, o discente deixa de ser um mero ouvinte das aulas, e passa a comportar-se de modo, a questionar e entender as relações entre os temas estudados e a prática (MORAN, 2018).

Os laboratórios virtuais, simulações computacionais e a modelagem computacional, podem produzir aulas interessantes, reflexivas e desafiadoras, que proporcionem um ensino mais ativo, resolvendo alguns problemas do ensino convencional (CARVALHO; OLIVEIRA, 2021).

O avanço no desenvolvimento das ferramentas computacionais tem viabilizado o contato dos estudantes com os sistemas de aquisição automatizados. Assim, a inserção de sistemas computacionais que demandam pouco investimento financeiro torna-se uma saída viável para que as aulas de Física sejam mais dinâmicas, criativas e significativas (CASTILHO et al., 2020). 
Todas as mudanças tecnológicas produzem reflexos no ensino, exigindo dos educadores novas metodologias, competências e habilidades para lidar com esse contexto. A utilização de recursos computacionais surge como uma estratégia de aprendizagem que pode despertar o interesse do estudante. Várias são as vantagens de se trabalhar com simulações computacionais (GAMA JÚNIOR, 2021). O sentido de utilizar teoria de aprendizagem com simulações computacionais faz surgir uma nova forma de produção científica da qual se aproximam as tarefas diárias da ciência contemporânea (GRECA et al., 2014).

Pesquisas declaram que, como qualquer outro mecanismo educacional, as simulações são dependentes da forma como são usadas. Desse modo, Smetana e Bell (2012), evidenciam o papel do professor na importância da orientação e acompanhamento dessa ferramenta, planejando e estruturando de acordo com o contexto da aplicação.

Moreira (2018) salienta:

Professores de Física são essenciais no ensino de Física. Mas suas condições de trabalho não Ihes permitem buscar um verdadeiro ensino que conduza a uma verdadeira aprendizagem de Física. Por outro lado, sua formação em Física é fraca. Além de serem formados com o ensino tradicional, das aulas expositivas e listas de problemas, tem pouca Física na graduação, quase nada de Física moderna e contemporânea. No seu ensino, não passam da Física clássica, iniciando com a Cinemática, na qual os alunos começam a não gostar da Física (MOREIRA, 2018, p.76).

É visível à preocupação do autor supracitado, em como resolver o problema de ensino e aprendizagem de Física, pois, ele aponta como uma das principais dificuldades que deve ser resolvida é a formação dos professores. É perceptível também que, o processo de ensinagem é complexo, depende de vários aspectos como: os educadores que colaboram na organização dos currículos escolares; estrutura física das escolas; os legisladores que criam leis e diretrizes para o sistema educacional; acesso à tecnologia; capacidade do docente, assim como o interesse do aprendiz.

Dentre os diversos procedimentos do professor em sala de aula enfatiza-se 0 desenvolvimento de projetos educacionais inovadores capazes de estimular a curiosidade e a criatividade dos alunos a partir da resolução de problemas que relacione o contexto ao cotidiano. Dessa maneira, a construção do conhecimento ocorre mediante interações sociais em sala de aula, a partir de soluções para as situações-problema apresentadas aos discentes de maneira colaborativa e significativa (MOREIRA; MASSONI, 2016; ANDRADE; SARTORI, 2018).

Diante disso, o professor precisa planejar nos mínimos detalhes a metodologia de ensino, pois o aluno, deve atuar como ser pensante e ativo durante todo o processo no ensino. O conhecimento demanda pesquisa e investigação dos aprendizes. Sugerir novos métodos desperta o interesse e a aprendizagem dos discentes, além de trazer o conhecimento próximo ao aluno e como resultado melhorar o aprendizado (ANDRADE; SARTORI, 2018).

$O$ avanço na qualidade do ensino de Física resulta de uma mudança de postura didático-pedagógica do professor, pois, considera-se que, para uma interação mais ativa em sala de aula, que estimule a participação e o interesse dos 
estudantes em relação aos conteúdos propostos, é fundamental a ressignificação do papel do professor em suas práxis pedagógicas (PEREIRA et al., 2017). Os autores mencionam a necessidade de uma na formação inicial dos docentes de maneira que estes repensem sobre suas estratégias didáticas de ensino.

O ensino de Física ao longo dos anos vem enfrentando várias adversidades e desafios. Objetivando melhorar o ensino e aprendizagem dos estudantes, tem se buscado gerar novas perspectivas que proporcionem a aprendizagem significativa (MOREIRA, 2018). Ao realizar essa pesquisa, pode-se afirmar que o ensino de Física no Ensino Médio precisa e deve ser otimizado. Direcionar como fazer para aprimorar não é difícil, laborioso é o desafio de potencializar para que todo sistema educacional opere de forma mais efetiva (MOREIRA, 2018).

\section{O QUE É APRENDIZAGEM SIGNIFICATIVA?}

Para Moreira (2012) a aprendizagem significativa é definida pela interação entre conhecimentos prévios e conhecimentos novos, ou seja, os novos conhecimentos só adquirem significado para o estudante quando há uma relação de importância entre aquilo que o aprendiz já sabe em sua estrutura cognitiva e o conhecimento que está sendo adquirido. [...] a este conhecimento, relevante à nova aprendizagem, o qual pode ser, um símbolo já significativo, um conceito, uma proposição, um modelo mental, uma imagem, David Ausubel $^{2}$ (1918-2008) chamava de subsunçor ${ }^{3}$ ou idéia-âncora.

Segundo Biasotto et al., (2020), os conhecimentos prévios, chamados por Ausubel de conceitos subsunçores, servem como âncoras, na construção de concepções, pois permitem relacionar novas informações aos conhecimentos já presentes na estrutura cognitiva do indivíduo. Assim, aquilo que o estudante já sabe por já ter assimilado em um determinado momento, servirá para ancorar um novo conhecimento.

Para Moreira (2012, p. 4), "subsunçor é, portanto, um conhecimento estabelecido na estrutura cognitiva do sujeito que aprende e que permite, por interação, dar significado a outros conhecimentos". Assim sendo, compreende como subsunçores os conceitos já preexistentes na estrutura cognitiva do aprendiz, permitindo dar significado real ao conhecimento adquirido.

"O subsunçor pode ser também uma concepção, uma proposição, um modelo, enfim um conhecimento prévio especificamente relevante para a aprendizagem significativa de determinados novos conhecimentos" (MOREIRA, 2012, p.4). Na verdade, a aprendizagem significativa se constitui, basicamente, sobre os subsunçores, portanto, o conhecimento prévio representa uma matriz organizativa para a estruturação do novo conhecimento. Os novos princípios e conceitos comumente são adquiridos de forma significativa, uma vez que estes funcionam como subsunções (AVILES; GALEMBECK, 2017).

O entendimento de como ocorre a aquisição de novos conhecimentos é caracterizado como propósito da teoria da aprendizagem significativa. Quando o

\footnotetext{
${ }^{2}$ David Ausubel (1918-2008), graduou-se em Psicologia e Medicina, doutorou-se em Psicologia do Desenvolvimento na Universidade de Columbia, onde foi professor no Teacher's College por muitos anos; dedicou sua vida acadêmica ao desenvolvimento de uma visão cognitiva à Psicologia Educacional.

3 "Nome que se dá a um conhecimento específico, existente na estrutura de conhecimentos do indivíduo, que permite dar significado a um novo conhecimento que lhe é apresentado ou por ele descoberto" (MOREIRA, 2012, pág. 02).
} 
estudante se interessa em aprender algo novo, entende-se que essa nova informação será armazenada em sua estrutura cognitiva (ROZAL et al., 2017).

Tendo em consideração o desafio de educar no século XXI, em tempos de novas tecnologias, torna-se essencial rever práticas pedagógicas que tencionem construir uma aprendizagem cada vez mais significativa. Assim, enfatizar o modo como ocorre o processo de aprendizagem é muito importante, pois é necessário que seja concedido sentido e significado ao que se aprende (MOREIRA, 2018). Para Vizzotto (2019, p. 154), "inicialmente, acreditava-se que aprender dependia de fatores externos ao indivíduo e que o contato com o mundo, por meio dos sentidos, proporcionaria a integração necessária para 'adquirir' conhecimentos".

A teoria de Ausubel pressupõe que a aprendizagem é significativa quando uma nova informação (conceito, ideia, suposição) adquire significado para o aluno. Para a informação fazer sentido, é preciso que se estabeleça uma analogia com as ideias que se encontram na sua estrutura cognitiva (conceitos subsunçores), onde as ideias do aluno estão organizadas. Desta forma, uma vez aprendido determinado conteúdo, o aluno é capaz de explicá-lo com suas próprias palavras (TIRONI et al., 2013, p. 3).

Com o intuito de romper com um ensino tradicional, que motiva tão pouco os alunos, faz-se necessário que os docentes realizem metodologias que possibilitem o acesso a saberes sobre o mundo e a prática da cultura digital, já que impactam em vários aspectos do cotidiano de forma acentuada. A inclusão dessas estratégias pode ser determinante para a aprendizagem significativa e autônoma pelos alunos.

E por que a aprendizagem é significativa? Porque possibilita dar significado a um novo conhecimento, seja de forma mediada, ou pela própria intervenção do aluno (MOREIRA, 2012).

Guerra (2011) afirma que um aluno apresentará dificuldades em prestar atenção em informações que não tenham vínculo com o contexto da sua realidade, ou que não sejam significativas para ele. Por isso, memorizamos as experiências filtradas pela atenção. Com isso, pode-se afirmar que a memória também é imprescindível para a aprendizagem significativa.

As práticas pedagógicas tradicionais, baseadas em métodos de memorização para repetição e a formação de docentes já não se mostram satisfatórias para a construção da aquisição do conhecimento em uma sociedade contemporânea com acentuado avanço tecnológico. Apoiado em Relvas (2010), quando se aprende com razão e com a emoção, sempre há algo a expressar relacionado ao que se aprende, pois, a aprendizagem torna-se autêntica.

$\mathrm{Na}$ prática, a maioria das escolas de um modo geral ainda continuam promovendo muito mais a aprendizagem mecânica (memorística) do que a significativa. Para Braathen (2012);

Aprendizagem Mecânica ocorre com a incorporação de um conhecimento novo de forma arbitrária, ou seja, o aluno precisa aprender sem entender do que se trata ou compreender o significado do porquê. $\mathrm{Na}$ Significativa, a aprendizagem ocorre com a incorporação de conhecimento novo na estrutura cognitiva do estudante, e pode ser associado a um conhecimento prévio, 
relacionado e relevante, já existente nessa estrutura cognitiva (BRAATHEN, 2012, p. 65).

O autor acima ainda afirma que a Aprendizagem Mecânica, acontece de maneira formal, o estudante aprende exatamente como foi abordado (decoreba), sem interpretação própria, ou seja, não é relacionado ao conhecimento prévio o novo conhecimento a ser assimilado. Um exemplo disso é o aluno estudar sobre calorimetria e não ter aprendido o conceito de temperatura e calor.

$\mathrm{Na}$ Aprendizagem Significativa, o aprendizado acontece com a inserção de conhecimento novo na estrutura cognitiva do aprendiz, e pode ser relacionado a um conhecimento prévio, já existente em sua cognição. Exemplo, o estudante já inseriu os conceitos de temperatura e calor para depois compreender sobre as trocas de energia térmica entre os corpos. A figura 1, mostra o processo de aprender mecanicamente e o processo de aprender significativamente (BRAATHEN, 2012).

FIGURA - Processo de aprendizagem Mecânica e de Aprendizagem significativa

O Conhecimento Significativo

O Conhecimento Mecânico

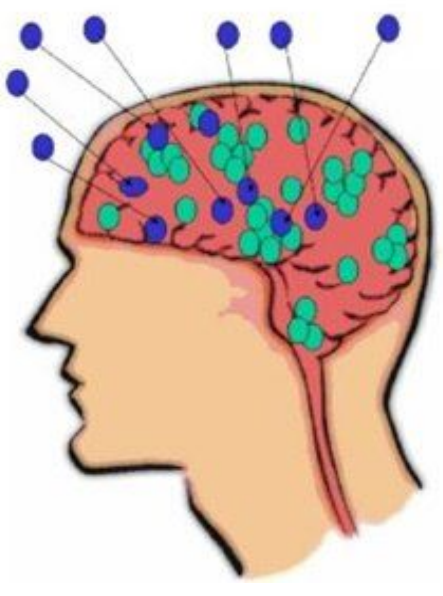

Fonte: BRAATHEN, (2012)

Braathen (2012), ressalta que o conhecimento mecânico se forma através de conceitos isolados na estrutura cognitiva, pois não tem conhecimento prévio para conectá-los de forma a permitir a integração e a inter-relação entre eles. O significativo é a aprendizagem com muitos conceitos (unidades de conhecimento) interligados.

Aires e Pilatti (2016) destacam que o estudante precisa estar interessado em aprender, e para que o aprendizado ocorra de fato, o conteúdo deve estar organizado e estruturado para ter significado. A aprendizagem significativa é desenvolvida com base na importância e no sentido que se dar ao novo assunto com algo que já foi vivenciado anteriormente, para que desperte no aluno a motivação em aprender. Segundo esses autores, o docente não ensina algo a alguém, ele apenas repassa um conteúdo que é internalizado pelo estudante e compreendido da maneira que ele entendeu. Se o aluno achar que o conceito repassado foi importante, ele aprende. Caso contrário, é necessário outro incentivo ENCICLOPÉDIA BIOSFERA, Centro Científico Conhecer - Jandaia-GO, v.18 n.37; p. 52 2021 
para adquirir o conhecimento. Desse modo, a aprendizagem depende de como os conceitos são abordados, ou seja, de como o aluno recebe as informações e do conhecimento prévio que ele tem sobre o tema explorado para que possa dominar os novos conceitos.

Considera ser importante que o professor tenha atenção com o currículo, no entanto, mesmo com aulas expositivas tradicionais, muitas mudanças de conceito que envolvem a aprendizagem significativa podem acontecer caso o educador não utilize de metodologias mais dinâmicas. Desse modo, mesmo a sala de aula que possui muitos estudantes, a falta do conhecimento prévio pode ser amenizada ou até mesmo resolvida quando é gerado um ambiente dinâmico e participativo, com efetivo envolvimento dos discentes (AIRES; PILATTI, 2016).

\section{NEUROCIÊNCIAS E A NECESSIDADE DO PROFESSOR NO AUXÍLIO E TRANSFORMAÇÃO DO PROCESSO DE ENSINO E APRENDIZAGEM}

Esta pesquisa destaca a importância da Neurociência, dos aspectos cognitivos na aprendizagem e as contribuições dessa área na educação, compreendendo a neurociência e o desenvolvimento cognitivo como indispensável no aprendizado do aluno. "A neurociência compreende o estudo do sistema nervoso e suas ligações com toda a fisiologia do organismo, incluindo a relação entre cérebro e comportamento" (VENTURA, 2010, p.123). Essa área da ciência tem relevante importância para a compreensão da estrutura, organização e funcionamento do cérebro (VIZZOTTO, 2019).

Se preconiza que a educação seja de qualidade em múltiplos conceitos Nardi e Scheneider (2012), mas, sobretudo, que professores formem sujeitos críticos e reflexivos. O estudo sobre neurociências deu início por volta do século XIX, realçando dois pesquisadores Hitzig e Fritsch. Pesquisadores ao estudarem o cérebro humano perceberam que este responde a mudanças efetivas, nas quais através de ensinamentos demonstraram que os estímulos ocorrem através de sinapses ${ }^{4}$ neurais, que se caracteriza em uma região do cérebro onde há uma comunicação com os neurônios e células musculares. Para Bortoli e Teruya (2017):

Os estudos sobre o cérebro apontam que as emoções contribuem para a aprendizagem porque auxiliam a passagem da memória de curto para a memória de longo prazo, assim como a motivação é indispensável para a liberação de substância responsável por mobilizar a atenção e reforçá-la na relação com o objeto que a afetou (p. 70).

O cérebro não para e suas funções cerebrais são ativadas por meio de circuitos, assim, os estímulos promovem a formação de sinapses "capacidade de fazer e desfazer ligações entre os neurônios como consequência das interações constantes com o ambiente externo e interno do corpo" (COSENZA; GUERRA, 2011, p. 36). Nesse sentido, quanto mais estímulos, mais sinapses são ativadas.

Uma característica predominante do sistema nervoso é a plasticidade cerebral, que se refere à capacidade que "o cérebro possui de se remodelar e remapear suas conexões depois de um dano, excluindo teorias antigas de que o

\footnotetext{
4 Conexões feitas entre os bilhões de neurônios presentes no nosso cérebro, que transmitem impulsos nervosos uns para os outro.
} 
cérebro seria imutável" (CHOPRA; TANZI, p. 46, 2013). Este conceito estabelece a base biológica da aprendizagem, ou seja, a capacidade de construir e descontruir ligações entre os neurônios com o ambiente externo e interno do corpo.

"A grande plasticidade de fazer e desfazer as associações existentes entre as células nervosas é a base da aprendizagem e permanece ao longo de toda vida". A aprendizagem apenas diminui com o passar do tempo, necessitando um esforço maior para que se aprenda (COSENZA; GUERRA, p.36, 2011).

Por possuir plasticidade, o cérebro necessita ser desafiado, estimulado e reorganizado todo o tempo. Pesquisas mostraram que o cérebro é constituído por um conjunto de sistemas complexos e flexíveis e para melhor entender a sua capacidade de aprendizagem, é necessário pesquisar os processos neurais de sua mudança. $O$ aprendizado ocorre através das modificações de comportamento e acontece no sistema nervoso por intermédio da plasticidade cerebral. As pessoas possuem potencialidade para aprender desde seu nascimento até a morte, sendo necessário para tanto disponibilizar as condições para que isso ocorra (COSENZA; GUERRA, 2011).

Em conformidade com Tiradentes et al., (2018) a neurociência tem por pilar contribuir com o professor em estratégias empregando as práticas desse conhecimento em sala de aula, estabelecendo oportunidades para que a mente se desenvolva, e ocasione alterações no funcionamento cerebral desempenhando papeis importantes na aprendizagem.

De acordo com Guerra (2011), apesar da série de conhecimentos provenientes dos estudos acerca da neurociência para o ensino e educação, esta não tem a capacidade de solucionar todas as dificuldades de aprendizagem, mas consegue consolidar métodos, que venham a melhorar o processo de ensino aprendizagem. A Neurociência proporciona para os educadores novas estratégias
de ensino e aprendizagem. Sendo assim, quando os estudantes são
estimulados e valorizados em sala de aula por meio de um método
dinâmico e prazeroso, surgem alterações na quantidade e qualidade
de conexões sinápticas, resultando em um processo cerebral
positivo, que aumenta as suas possibilidades de resultados eficazes
(SOUSA, ALVES, 2017).

Nessa perspectiva, é importante analisar a importância de proporcionar diversos estímulos aos alunos, pois, além de terem a capacidade de influenciar no desenvolvimento cerebral, estes trazem à tona a importância da motivação para aprender. Para que isto ocorra, o professor necessita propor atividades aos alunos que desperte a curiosidade destes avançar no processo de aprendizagem. Para Damasceno Júnior e Romeu (2021):

Um modelo de aprendizagem baseado em uma mera transmissão de conteúdos será ineficiente, haja vista que pouco estabelece vínculo/ligações com informações já disponíveis no cérebro do indivíduo (p.13).

É essencial que o professor realize estratégias ativas baseadas na metodologia de contextualização no processo da aprendizagem, que propicie relações entre os conhecimentos prévios e os conhecimentos científicos dos ENCICLOPÉDIA BIOSFERA, Centro Científico Conhecer - Jandaia-GO, v.18 n.37; p. 54 
aprendizes, bem como ao desenvolvimento de habilidades e competências (DAMASCENO JÚNIOR; ROMEU, 2021).

Conforme Fonseca (2016), a memória não pode ser dissociada da aprendizagem, pois uma das formas de desenvolvê-la é fazer com que o conhecimento novo esteja de acordo com as expectativas, e que tenha ligações com experiências anteriores considerada como importante para o estudante.

A memória associa, portanto, as funções de recepção e as funções de expressão, pois estas não se dão sem as funções de armazenamento, compreensão, integração e formulação rememorização. Esquecer é desaprender. Esquecer coisas é provavelmente, o resultado de não as ter aprendido ou de não as ter organizado interiormente de forma suficiente. (FONSECA, 2016, p. 156).

A memória é transitória, e se não houver novas ativações da mesma experiência, o aprendizado não é consistente. Sendo assim, é fundamental que o aluno receba estímulos positivos que impulsione a aprendizagem significativa, caso contrário, poderá existir falhas na memorização de algumas experiências vivenciadas (SOUSA; ALVES, 2017).

Cosenza e Guerra (2011) declaram ainda que não se aprende tudo o que estuda de um dia para o outro e muito menos o que apenas estuda na aula. É significativo que temas explanados possam ser considerados em diferentes contextos, [...] "a aprendizagem se traduz pela formação e consolidação das ligações entre as células nervosas. É fruto de modificações químicas e estruturais no sistema nervoso de cada um" (COSENZA; GUERRA, 2011, p. 38).

\section{CONSIDERAÇÕES FINAIS}

Perante o exposto na pesquisa, é relevante que as perspectivas de ensino possam ser centradas no aluno. Diante disso, os professores podem proporcionar estratégias de ensino que ampliem e proporcionem motivação para que os alunos sintam vontade em aprender. Ao gerar essas situações o docente passa a ser um facilitador da aprendizagem, sempre em busca de novos conhecimentos que irão contribuir para a aprendizagem de qualidade.

O ensino da Física além de contribuir para novas tecnologias propicia a formação de uma cultura científica que oportuniza ao aluno a interpretação de fenômenos e processos naturais, viabiliza a articulação de toda uma visão de mundo e de uma percepção dinâmica do universo.

Aprender significativamente consiste em desenvolver e caracterizar experiências e conhecimentos já existentes. É importante evidenciar que os conteúdos abordados sejam de relevância para o estudante, pois é necessário que o mesmo demonstre interesse para estudar.

Os estudos sobre neurociência são importantes meios para demonstrar a importância de conhecer as capacidades cerebrais dos seres humanos e suas possíveis situações que podem comprometer o aprendizado. Como foi apresentado no contexto do trabalho, a capacidade humana de aprender resulta de vários fatores.

De acordo com o panorama, é considerado que uma aprendizagem significativa depende de diversos elementos e comportamentos, e um aspecto bastante considerável é o desempenho do professor. Segundo as pesquisas, 
consegue-se perceber a importância das práticas pedagógicas desenvolvidas pelos educadores, estas por sua vez, fazem conexão do aluno com o conhecimento no processo de aprendizagem. Ensinar não é apenas transmitir o conhecimento é envolver completamente os aprendizes em sua formação tornando-os sujeitos pensantes e críticos capazes de obterem uma aprendizagem significativa.

Embasado nas pesquisas e no desenvolvimento deste artigo, percebe-se que para ocorrer uma aprendizagem significativa se faz necessário o entendimento de como se dá o processo de aprendizagem no cérebro. Assim, as estratégias de ensino que possuem maiores chances na aquisição do aprendizado, são geralmente as que consideram a maneira como o cérebro aprende.

Desta maneira, é possível repensar metodologias que possam ser capazes de preencher as lacunas ou carências implicadas nos processos de aprendizagem. $O$ aprender vai além das salas de aula, a escola não é a única responsável pelo conhecimento, a educação tem um conceito muito mais abrangente do que os conteúdos ministrados, significa um processo contínuo de aprendizagem emocional e cognitivo. É relevante para o ensino de Física, ensinar de forma significativa e a contribuição da neurociência com explicações científicas a respeito da estrutura e funcionamento do cérebro, auxilia para que os docentes possam melhorar suas estratégias de forma a incorporar a Teoria da Aprendizagem Significativa em sala de aula.

\section{REFERÊNCIAS}

ANDRADE, J. P.; SARTORI, J. O professor autor e experiências significativas na educação do século XXI: estratégias ativas baseadas na metodologia de contextualização da aprendizagem. In J. Moran \& L. Bacich, Metodologias ativas para uma educação inovadora: uma abordagem teórico-prática ( $p p .129-152$ ). Porto Alegre: Penso, 2018.

AIRES, J. P.; PILATTI. L.; A. Aprendizagem significativa por meio do ensino adaptativo. Revista Espacios v. 37, n. 29, p. 18, 2016. Disponível em: http://www.revistaespacios.com/a16v37n29/16372918.html. Acesso em: 09 ago. 2021.

AVILES, I.; E.; C.; GALEMBECK, E. Que é aprendizagem? Como ela acontece? Como facilitá-la? Um olhar das Teorias de Aprendizagem Significativa de David Ausubel e Aprendizagem Multimídia de richard mayer. Aprendizagem Significativa em Revista/Meaningful Learning Review , v. 7, n. 3,. p. 01-19, 2017. Disponível em: http://www.if.ufrgs.br/asr/artigos/Artigo_ID114/v7_n3_a2017.pdf Acesso em: 05 ago. 2021.

AUSUBEL, D. P. Aquisição e Retenção de Conhecimentos: uma Perspectiva Cognitiva. Paralelo Editora, LTDA, Lisboa. Traduzido por Lígia Teopisto, 2002.

BIASOTTO, L. C.; FIM, C. F.; KRIPKA, R. M. L.; A teoria da aprendizagem significativa de David Paul Ausubel: uma alternativa didática para a educação matemática. Brazilian Journal of Development. Curitiba, v. 6, n. 10, p. 8318783201, oct/2020. Disponível em: file://C:/Users/Positivo/Downloads/19068-48998-1PB.pdf Acesso em: 10 ago. 2021. DOI: 10.34117/bjdv6n10-668. 
BORTOLI, B.; TERUYA, T. K. Neurociência e educação: os percalços e possibilidades de um caminho em construção. Revista Imagens da Educação, v. 7, n. 1, p. 70-77, 2017. Disponível em: http://www.periodicos.uem.br/ojs/index.php/ImagensEduc/index . Acesso em 14 jul. 2021. DOI: https://doi.org/10.4025/imagenseduc.v7i1.32171.

BRAATHEN, P. C. Aprendizagem mecânica e aprendizagem significativa no processo de ensino-aprendizagem de Química. Revista Eixo, v. 1,n.1, janjun/2012. Disponível em: http://revistaeixo.ifb.edu.br/index.php/RevistaEixo/article/view/53/29. Acesso em: 05 ago. 2021.

BRASIL, Ministério da Educação (MEC). Coordenação de Aperfeiçoamento de Pessoal de Nível Superior (CAPES). Diretoria de Avaliação (DAV). Documento de Área. Área 46. Ensino. 2019. Disponível em: https://www.gov.br/capes/ptbr/centrais-de-conteudo/ENSINO.pdf . Acesso em 13 ago. 2021.

BROCKINGTON, G.; Neurociência e Ensino de Física: limites e possibilidades em um campo inexplorado. Revista Brasileira de Ensino de Física, v. 43, suppl. 1, e20200430 (2021). DOI: https://doi.org/10.1590/1806-9126-RBEF-2020-0430.

CARVALHO, P. S., OLIVEIRA, A. C. S. Uso de simulações computacionais em aulas de Física: um estudo sobre a sua influência no processo de aprendizagem dos estudantes com deficiência. Tear: Revista de Educação, Ciência e Tecnologia, v.10, n.1, 2021.

CASTILHO, W. S.; OLIVEIRA, D. L.; DUTRA, M. V. G.; O ensino de Física e a Aprendizagem Significativa: um kit experimental com Arduino para o ensino de queda livre. Experiências em Ensino de Ciências, v.15, n.3, 2020. Disponível em: https://fisica.ufmt.br/eenciojs/index.php/eenci/article/view/781/734 Acesso em: 01 ago. 2021.

CHOPRA, D.; TANZI, R. E. Supercérebro: como expandir o poder transformador da sua mente. Tradução de Bianca Albert, Eliana Rocha, Rosane Albert. São Paulo: Alaúde Editorial, 2013.

COSENZA, R. M.; GUERRA L. B. Neurociência e Educação. Porto Alegre: Artmed, 2011.

DAMASCENO JÚNIOR, J. A.; ROMEU, M. C.; Contribuições da Neurociência e da Aprendizagem Significativa para o ensino de Física e de conceitos básicos de Astronomia: algumas aproximações preliminares. Revista Prática Docente, v. 6, n. 2, e033, 2021. Disponível em: http://200.129.244.167/periodicos/index.php/rpd/article/view/994/478

Acesso em: 30 jul. 2021. DOI: http://doi.org/10.23926/RPD.2021.v6.n2.e033.id994.

FONSECA, V. Dificuldade de aprendizagem: abordagem neuropsicopedagógica. Rio de Janeiro: Wak editora, 2016. 
GAMA JÚNIOR, R. C., NEIDE, I. G., MOREIRA, A. M. Atividades experimentais e computacionais no ensino de física: uma revisão da literatura. Revista Brasileira de Ensino de Ciências e Matemática - RBECM, Passo Fundo, v. 4, n. 1, p. 348-369, jan./jun. $2021 . \quad$ Disponível Em: http://seer.upf.br/index.php/rbecm/article/view/11576/114115877. Acesso em: 12 ago. 2021

GRECA, I. M., SEOANE, E., ARRIASSECQ, I. Epistemological issues concerning computer Simulations in science and their implications for science education. Science \& Education, Millsboro, v. 23, p. 879-921, 2014. DOI: 10.1007 / S11191013-9673-7.

GUERRA, L. B. O diálogo entre a neurociência e a educação: da euforia aos desafios e possibilidades. Revista Interlocução, v.4, n.4, p.3-12, 2011, publicação semestral, junho/2011. Disponível em: https://www2.icb.ufmg.br/neuroeduca/arquivo/texto_teste.pdf. Acesso em: 15 jul. 2021.

MORAN, J. Metodologias ativas para uma aprendizagem mais profunda. In J. Moran, \& L. Bacich, Metodologias ativas para uma educação inovadora: uma abordagem teórico - prática, p. 2-26. Porto Alegre: Penso, 2018.

MOREIRA, A. M. O que é afinal Aprendizagem Significativa? Revista cultural La Laguna Espanha, 2012. Disponível em: http://moreira.if.ufrgs.br/oqueeafinal.pdf. Acesso em: 22 jul. 2021.

94, p.73-80, $2018 . \quad$ Disponível em: https://www.revistas.usp.br/eav/article/view/152679/149153. Acesso em: 22 jul. 2021. DOI: https://doi.org/10.1590/s0103-40142018.3294.0006

MOREIRA, M.; MASSONI, N. Noções básicas de epistemologias e teorias de aprendizagem como subsídios para a organização de sequências de ensino aprendizagem em ciências/física. São Paulo: Livraria da Física, 2016.

NARDI, E. L.; SCHNEIDER, M. P.; Qualidade na educação básica: entre significações, políticas e indicadores In: Revista Educação em Questão. Natal, v. 42, n. 28, p. 227-250, jan./abr. 2012. Disponível em: https://periodicos.ufrn.br/educacaoemquestao/article/view/4059/3326 Acesso em: 10 ago. 2021.DOI:

RELVAS, M. P. Neurociência e educação: potencialidades dos gêneros humanos na sala de aula. 2. ed. Rio de Janeiro: Wak Ed., 2010.

ROCHA, L. C. T.; ALENCAR, M. V.; ANTONOWISKI, R. Dificuldades encontradas para aprender e ensinar Física moderna. Scientific Electronic Archives Issue, v. 10, n. 4, August/ 2017. ISSN: 2316-9281. Disponível em: 384-Arquivo word (.docx)1718-1-10-20170810.pdf . Acesso: 02 ago. 2021. 
ROZAL, E. F.; SOUZA, E.; S.; R.; SANTOS, N.; T. Aprendizagem em matemática, aprendizagem significativa e neurociência na educação dialogando aproximações teóricas. Revista REAMEC, Cuiabá-MT, v. 5, n. 1, p. 143-164, 2017. Disponível em: https://doaj.org/article/40292da042374857b93ffdc59d3df699. Acesso em: 09 jul. 2021. DOI: 10.26571/2318-6674.a2017.v5.n1.p143-163.i5349.

PEREIRA, R.; F.; FUSINATO, P.; A.; GIANOTTO, D.; E.; P. A prática pluralista na formação inicial de professores de Física. Ensaio Pesquisa em Educação em Ciências (Belo Horizonte), Belo Horizonte, v. 19, e2682, 2017. Disponível em: https://www.scielo.br/j/epec/a/DsXpnsxgwLJ79Tbd8dNBBty/?lang=pt\&format=pdf.

Acesso em: 01 ago. 2021. DOI: http://dx.doi.org/10.1590/1983-21172017190126.

Disponível em: https://www.scielo.br/scielo.php?script=sci_arttext\&pid=S198321172017000100220\&lng=pt\&tIng=pt . Acesso em: 01 ago. 2021. DOI: http://dx.doi.org/10.1590/1983-21172017190126.

SILVA, E. L.; MENEZES, E. L. S. Metodologia da pesquisa e elaboração de dissertação. 3. ed. rev. atual. Florianópolis: Laboratório de Ensino a Distância da UFSC, $2001.2121 \mathrm{p}$ Disponível em: http://cursos.unipampa.edu.br/cursos/ppgcb/files/2011/03/Metodologia-da-Pesquisa3a-edicao.pdf. Acesso em: 29 de ago. 2021.

SMETANA, L.; K.; BELL, R.; L . (2012). Simulações de computador para apoiar o ensino e aprendizagem de ciências: uma revisão crítica da literatura . International Journal of Science Education ,v. 34, n. 9, p.1337 - 1370. 2012. Disponível em: http://www.tandfonline.com/doi/abs/10.1080/09500693.2011.605182. Acesso em: 27 ago. 2021.

SOUSA, A. M. O. P.; ALVES, R. R. N. A Neurociência na formação dos educadores e sua contribuição no processo de aprendizagem. Revista Psicopedagogia. v. ed. $105.2017 . \quad$ Disponível em: https://cdn.publisher.gn1.link/revistapsicopedagogia.com.br/pdf/v34n105a09.pdf. Acesso em: 03 ago. 2021.

TIRADENTES, C. P.; SANTOS, K. S.; LOPES, R. A. S. Neurociências e desenvolvimento cognitivo: implicações para a educação. REVELLI - ISSN 19846576 v.10 n.4, p. 83-100, Dez/2018. p. 83-100 - Inhumas/Goiás Brasil. Disponível em: 6455-Texto do artigo-31894-2-10-20190303 (1).pdf. Acesso em: 08 ago. 2021.

TIRONI, C. R.; SCHMIT, E.; SCHUHMACHER, V. R. N.; SCHUHMACHER, E.; A Aprendizagem Significativa no Ensino de Física Moderna e Contemporânea. IX Encontro Nacional de Pesquisa em Educação em Ciências Águas de Lindóia, SP - 10 a 14 de Novembro de 2013. Disponível em: http://abrapecnet.org.br/atas_enpec/ixenpec/atas/resumos/R0986-1.pdf. Acesso em: 10 ago. 2021.

VENTURA, D. F.; Um Retrato da Área de Neurociência e Comportamento no Brasil. Psicologia: Teoria e Pesquisa, v. 26, n. especial, p. 123-129. 2010. Disponível em: 
https://www.scielo.br/j/ptp/a/FWkB6QRJ4hkjJbqq66sfjcd/?format=pdf\&lang=pt Acesso: 20 jul. 2021.

VIZZOTTO, P. A.; A Neurociência na formação do professor de Física: Análise curricular das licenciaturas em Física da região Sul do Brasil. Revista Insignare Scientia, v.2, n. 2, p. 150-165, 2019. Disponível em: https://doaj.org/article/08bbea670c1049afa9d6c34aaf8672d6. Acesso em: 10 jul. 2021 